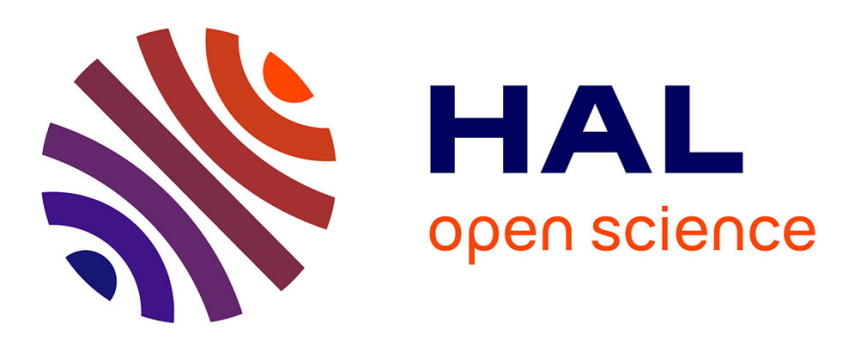

\title{
Reactivity of the Excited States of the H-Cluster of FeFe Hydrogenases
}

\author{
Matteo Sensi, Carole Baffert, Claudio Greco, Giorgio Caserta, Charles \\ Gauquelin, Laure Saujet, Marc Fontecave, Souvik Roy, Vincent Artero, \\ Philippe Soucaille, et al.
}

\section{To cite this version:}

Matteo Sensi, Carole Baffert, Claudio Greco, Giorgio Caserta, Charles Gauquelin, et al.. Reactivity of the Excited States of the H-Cluster of FeFe Hydrogenases. Journal of the American Chemical Society, 2016, 138 (41), pp.13612-13618. 10.1021/jacs.6b06603 . hal-01400732

\section{HAL Id: hal-01400732 \\ https://hal.science/hal-01400732}

Submitted on 23 Jul 2019

HAL is a multi-disciplinary open access archive for the deposit and dissemination of scientific research documents, whether they are published or not. The documents may come from teaching and research institutions in France or abroad, or from public or private research centers.
L'archive ouverte pluridisciplinaire HAL, est destinée au dépôt et à la diffusion de documents scientifiques de niveau recherche, publiés ou non, émanant des établissements d'enseignement et de recherche français ou étrangers, des laboratoires publics ou privés. 


\title{
Reactivity of the excited states of the $\mathrm{H}$-cluster of FeFe hydrogenases
}

\author{
Matteo Sensi, ${ }^{\text {a,g }}$ Carole Baffert, ${ }^{\text {a }}$ Claudio Greco, ${ }^{\text {b }}$ Giorgio Caserta, ${ }^{\text {c }}$ Charles Gauquelin, ${ }^{\text {d }}$ \\ Laure Saujet, ${ }^{\mathrm{e}}$ Marc Fontecave, ${ }^{\mathrm{c}}$ Souvik Roy, ${ }^{\mathrm{f}}$ Vincent Artero, ${ }^{\mathrm{f}}$ Philippe Soucaille, ${ }^{\mathrm{d}}$ Isabelle \\ Meynial-Salles, ${ }^{d}$ Hervé Bottin, ${ }^{e}$ Luca de Gioia, ${ }^{9}$ Vincent Fourmond, ${ }^{a}$ Christophe Léger ${ }^{a *}$ and \\ Luca Bertini ${ }^{* *}$
}

a Aix Marseille Université, CNRS, BIP UMR 7281, 13402, Marseille, France.

b Department of Earth and Environmental Sciences, Milano-Bicocca University, Piazza della Scienza 1, Milan, 20126, Italy.

c Laboratoire de Chimie des Processus Biologiques, UMR 8229 CNRS, Collège de France, Université Paris 6, 11 Place Marcelin Berthelot, 75231, Paris CEDEX 05, France.

d Université de Toulouse, INSA, UPS, INP, LISBP, INRA:UMR792,135 CNRS:UMR 5504, avenue de Rangueil, 31077 Toulouse, France

e Institut de Biologie et de Technologies de Saclay IBITECS, SB2SM, F-91191 Gif sur

Yvette, France / Institut de Biologie Intégrative de la Cellule I2BC, UMR 9198, CEA, CNRS, Université Paris Sud, F-91191 Gif sur Yvette, France

f Laboratoire de Chimie et Biologie des Métaux, Univ. Grenoble Alpes, CNRS, CEA, 17 rue des Martyrs, 38054 Grenoble, France.

g Department of Biotechnologies and Biosciences, University of Milano-Bicocca, Piazza della Scienza 2, 20126 Milan, Italy.

leger@imm.cnrs.fr, luca.bertini@unimib.it

\section{Abstract}

FeFe hydrogenases catalyze $\mathrm{H}_{2}$ oxidation and formation at an inorganic active site (the "H-cluster"), which consists of a $\left[\mathrm{Fe}_{2}(\mathrm{CO})_{3}(\mathrm{CN})_{2}\right.$ (dithiomethylamine)] subcluster covalently attached to $\mathrm{a} \mathrm{Fe}_{4} \mathrm{~S}_{4}$ subcluster. This active site is photosensitive: visible light has been shown to induce the release of exogenous $\mathrm{CO}$ (a reversible inhibitor of the enzyme), shuffle the intrinsic $\mathrm{CO}$ ligands, and even destroy the $\mathrm{H}$-cluster. These reactions must be understood because they may negatively impact the use of hydrogenase for the photoproduction of $\mathrm{H}_{2}$. Here we explore in great details the reactivity of the excited states of the $\mathrm{H}$-cluster under catalytic conditions by examining, both experimentally and using TDDFT calculations, the simplest photochemical reaction: the binding and release of exogenous $\mathrm{CO}$. A simple dyad model can be used to predict which excitations are active. This strategy could be used for probing other aspects of the photoreactivity of the H-cluster. 


\section{Introduction}

Hydrogenases are metalloenzymes that oxidize and produce dihydrogen. ${ }^{1,2,3}$ They are involved in the bioenergetic metabolism of most microorganisms. The observation that light reverses the inhibition by $\mathrm{CO}$ of certain hydrogenases was made soon after these enzymes were first identified in the 1930's; the photosensitivity of the CO-bound complex and the competitive character of the inhibition were used to demonstrate that both exogenous $\mathrm{CO}$ and substrate $\mathrm{H}_{2}$ bind to an active site iron atom. ${ }^{4}$ Now we know that there are two types of hydrogenase active sites, and that the photorelease of $\mathrm{CO}$ under catalytic conditions was only observed with the so-called "FeFe hydrogenases" (see however ref 5 for a report of $\mathrm{CO}$ photorelease from NiFe hydrogenase under cryogenic conditions).

The active site of $\mathrm{FeFe}$ hydrogenase is a $\left[\mathrm{Fe}_{2}(\mathrm{CO})_{3}(\mathrm{CN})_{2}\right.$ (dithiomethylamine)] subcluster covalently attached to a $\mathrm{Fe}_{4} \mathrm{~S}_{4}$ subcluster, as depicted in fig $1 \mathrm{~A} .^{6-9}$ The $2 \mathrm{Fe}$ subcluster bears terminal and bridging intrinsic $\mathrm{CO}$ and $\mathrm{CN}^{-}$ligands. The binding of exogenous $\mathrm{CO}$ to the "distal" $\mathrm{Fe}$ (outermost, $\mathrm{Fe}_{\mathrm{d}}$ ) of the active site in the $\mathrm{H}_{\mathrm{ox}}$ redox state ( $F e^{\prime} F e^{\prime \prime}$ ) yields the inhibited $\mathbf{H}_{\text {ox }}-\mathbf{C O}$ form of the enzyme. ${ }^{10}$ Exogenous $\mathrm{CO}$ dissociates to give back the active form of the $\mathrm{H}$-cluster upon irradiation with white light either at room temperature ${ }^{4,11}$ or at cryogenic temperature below $20 \mathrm{~K}$, but other photoproducts are formed upon irradiation at cryogenic temperature in the range $20-80 \mathrm{~K}^{12-15}$ Albracht, Stripp and coworkers have also shown that the $\mathrm{CO}$ ligands that are bridging and terminally bound on $\mathrm{Fe}_{\mathrm{d}}$ can be exchanged with extrinsic $\mathrm{CO}$ upon illumination; ${ }^{14,15,16}$ this shuffling of the coordination sphere of $\mathrm{Fe}_{\mathrm{d}}$ is relevant to the reversible inactivation of the enzyme that occurs under oxidizing conditions. ${ }^{17}$ The photosensitivity of the iron-carbonyl bonds can also lead to photo-induced damage when the enzyme is illuminated in the absence of exogenous CO; indeed, according to a study of the hydrogenase from $D$. desulfuricans, ${ }^{14,15}$ long exposure to "normal laboratory light" at room temperature destroys the H-cluster. Such photodamage adds biotechnological barriers that will limit the effectiveness of $\mathrm{H}_{2}$-photoproduction processes, whether they consist in using $\mathrm{FeFe}$ hydrogenases attached to photosensitisers ${ }^{18-19}$ or microorganisms that couple photosynthesis to hydrogen production. ${ }^{20}$ NiFe hydrogenases, in contrast, are apparently not damaged by light. ${ }^{21,22}$

The photolability of $\mathrm{CO}$ is a typical aspect of the reactivity of all transition metal carbonyl complexes, which has been investigated in dinuclear models of the H-cluster. ${ }^{24} \mathrm{UV}$ irradiation triggers $\mathrm{CO}$ photolysis in model compounds such as $\mu$-propanedithiolate- $\mathrm{Fe}_{2}(\mathrm{CO})_{6}$ and its derivatives; this has been studied using ultrafast transient IR spectroscopy, ${ }^{25,26}$ and supported by Density Functional Theory (DFT) calculations. ${ }^{27}$ This reactivity is very solvent and ligand-dependent, and more complex than in the enzyme, probably because the protein that surrounds the active site prevents certain transformations. Time Dependent DFT (TDDFT) simulations shed light on the early stages of the photodynamics, showing that CO is loosely bound on the low energy excited state surfaces, and that the photoreactivity strongly depends on the coordination sphere of the iron atoms. ${ }^{28}$ 


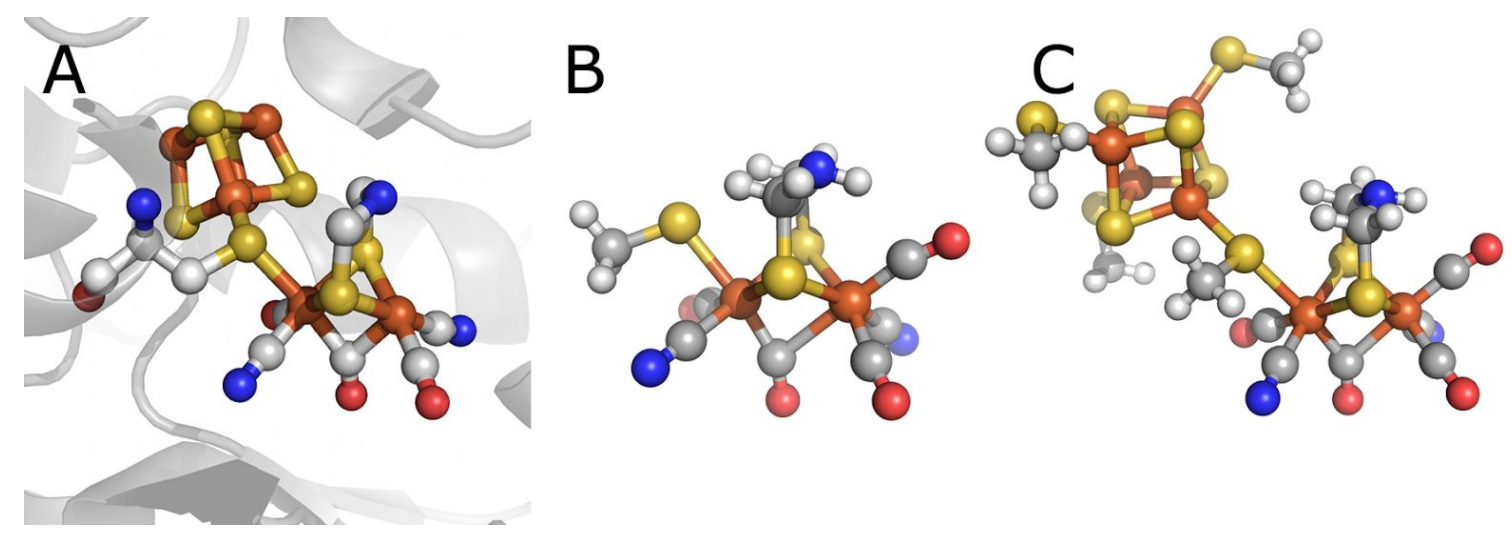

Figure 1. The H-cluster of hydrogenase. Panel A: the structures of the active site of C. acetobutylicum FeFe hydrogenase, adapted from pdb 3C8Y. ${ }^{23}$ Panels $B$ and C: the two models of $\boldsymbol{H}_{\mathrm{ox}}-\mathrm{CO}$ used in our TDDFT calculations.

Here we examine in great details, both experimentally and theoretically, the effect of visible irradiation on the simplest reaction of the $\mathrm{H}$-cluster: binding and release of the extrinsic inhibitor $\mathrm{CO}$. We compare the results obtained with three different $\mathrm{FeFe}$ hydrogenases and we examine for the first time how wavelength and light power affect the kinetics of inhibition under turnover conditions. The results are explained by TDDFT calculations of the electronic spectra and excited state PES topologies of two different $\mathrm{H}_{\mathrm{ox}}-\mathrm{CO}$ models, which show how the photodynamics of the system depends on the nature and excitation energy of the electronic transitions considered. A very simple description of the system in terms of a donor-acceptor molecular dyad system proves useful for identifying which excitations contribute to $\mathrm{CO}$ photolysis, although we conclude that intramolecular charge transfer is not the main photochemical process resulting in $\mathrm{CO}$ release.

\section{Results/ Electrochemistry}

We have previously described a method for measuring the rates of $\mathrm{CO}$ binding and release to/from hydrogenases. ${ }^{29,30}$ Briefly, a tiny amount of purified enzyme is either adsorbed or covalently attached ${ }^{31}$ to a rotating disc electrode and inserted into the $\mathrm{H}_{2}$-saturated solution of an electrochemical cell. Catalytic $\mathrm{H}_{2}$ oxidation results in a positive current whose magnitude is proportional to turnover rate. The enzyme is repeatedly exposed to $\mathrm{CO}$ by injecting a small amount of CO-saturated buffer in the electrochemical cell; the concentration of inhibitor instantly increases and then decays because $\mathrm{CO}$ is constantly flushed away from the cell by the flow of $\mathrm{H}_{2}$; the decay is exponential, ${ }^{32,33}$ as indicated in fig $2 \mathrm{~A}$, with time constant $\tau$. The resulting change in catalytic current (turnover rate) is illustrated in fig 2B. The current decreases after each injection at a rate that depends on the 2 nd order rate constant of $\mathrm{CO}$ binding to the enzyme $\left(k_{\text {in }}\right)$, and returns to its initial value after the $\mathrm{CO}$ concentration goes back to zero, at a rate that depends on the 1st order rate constant of $\mathrm{CO}$ release $\left(\mathrm{k}_{\text {out }}\right)$ and on the value of $\tau$. The change in current can be analyzed to measure $k_{\text {in }}$, $k_{\text {out }}$ and $\tau$ (when experiments such as in that in fig 2 are analysed, the value of $\tau$ is forced to be the same in the fitting procedure for all four injections). 
Here we describe how the irradiation of the enzyme changes the kinetics of binding and release of $\mathrm{CO}$ under turnover conditions. The experimental set-up which we used in this investigation is such that the parallel beam of a monochromatic laser diode $(\lambda=405,450$, 532 , or $635 \mathrm{~nm}$ ) is directed upward, towards the electrode surface, across a quartz window at the bottom of the thermostated electrochemical cell. The experiment in fig. 2 was performed by adding the same amount of $\mathrm{CO}$ four times in a row, the first time in the dark (actually, with the low intensity of the light of the lab), and then after increasing stepwise the power output of the diode, $P$, as indicated.

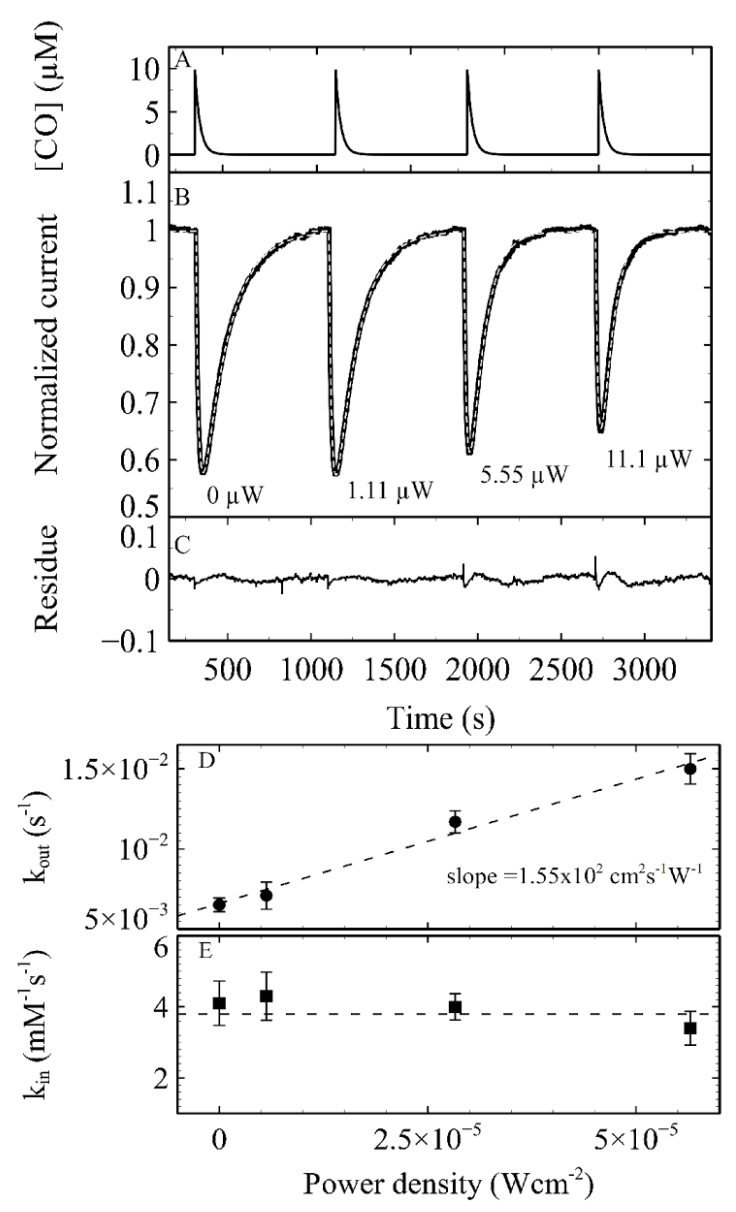

Figure 2.

Electrochemical experiment showing the effect of $450 \mathrm{~nm}$ irradiation on the inhibition by $\mathrm{CO}$ of the $\mathrm{FeFe}$ hydrogenase from M. elsdenii. Data obtained with the FeFe hydrogenases from $\mathrm{C}$. acetobutylicum and $C$. reinhardtii are shown in Supporting information section 3.1 (Supplementary Fig. 18 and 19).

Panel A shows the change in CO concentration against time, panel $B$ shows the resulting change in turnover rate and the fit of the kinetic model (dotted line), adjusting four values of $k_{i n}$, four values of $k_{\text {out }}$, and a single value of $\tau$. Panel $C$ shows the residue of the fit. The fit returned the values of the rate constants shown in panels $D$ and $E$. The $Y$-errors show the standard deviations observed in two independent experiments (the error on $k_{\text {in }}$ includes the error in the value of $\left.[\mathrm{CO}]_{0}\right) . p\left(\mathrm{H}_{2}\right)=1 \mathrm{~atm},[\mathrm{CO}]_{0}=10$ $\mu M, \tau=18 \mathrm{~s}, p H=7, T=30^{\circ} \mathrm{C}$. Electrode rotation rate $=3000 \mathrm{rpm}$.

Fig $2 \mathrm{~B}$ shows that all things being equal, the more powerful the $450 \mathrm{~nm}$ light, the less pronounced the inhibition. The effect is small, but it is revealed by the fit of the model (dotted line) which allows the values of $k_{\text {in }}$ and $k_{\text {out }}$ to be precisely measured. Fig 2D shows that illumination with violet/blue light ( 405 or $450 \mathrm{~nm}$ ) has a significant effect on $k_{\text {out }}$ (up to three fold at maximal power) and none on $k_{\text {in }}$. Green or red light (532 or $635 \mathrm{~nm}$ ) has an effect neither on $\mathrm{CO}$ binding nor on $\mathrm{CO}$ release. We show in fig 3 the slope of the linear change in $k_{\text {out }}$ as a function of wavelength (expressed as a cross section) against power density, for experiments carried out with three distinct FeFe hydrogenases: those from C. reinhardtii, ${ }^{34}$ M. elsdenii ${ }^{35}$ and C. acetobutylicum..$^{23}$ The enzyme from C. reinhardtii has no other cofactor than the $\mathrm{H}$-cluster whereas the other two bear additional electron-transferring $\mathrm{FeS}$ clusters. ${ }^{1,23,34,35}$ In all cases, only violet/blue light $(\lambda<500 \mathrm{~nm})$ has a detectable effect on $k_{\text {out }}$. The effect is about the same for all three enzymes (although its magnitude decreases in the 
order M. eldensii > C. reinhardtii > C. acetobutylicum, for reasons that cannot be elucidated at that point). Therefore, our experiments reveal an intrinsic property of the conserved $\mathrm{H}$-cluster.

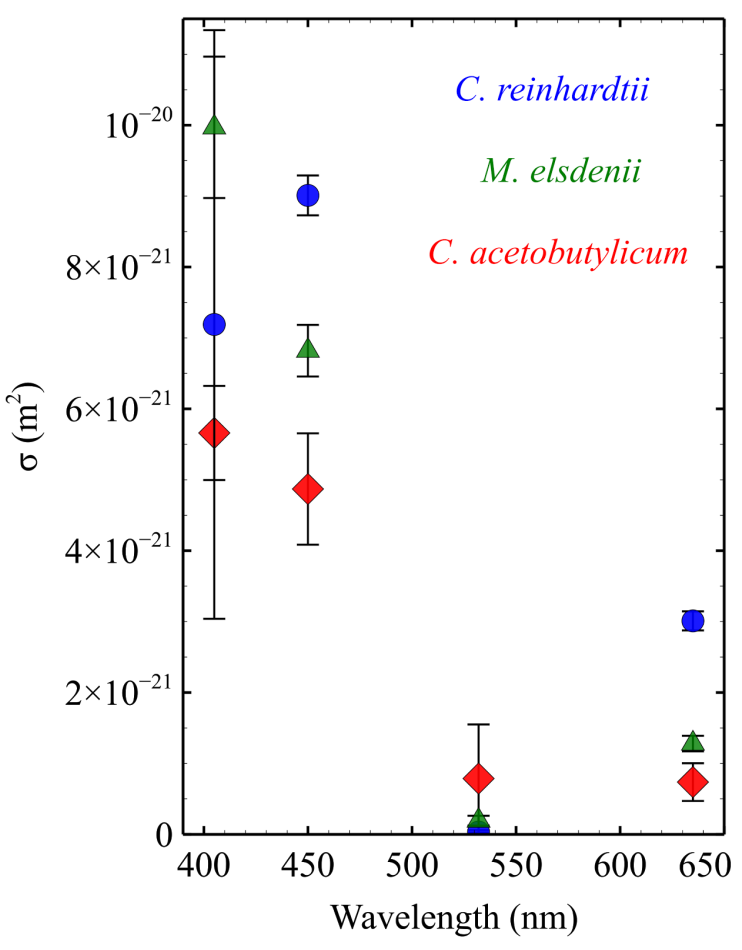

\section{Figure 3.}

Dependence on wavelength of the effective cross section for the photodissociation of $\mathrm{CO}$ (calculated from the slope of the line in fig $2 D$ multiplied by $h v$ ) on the rate of CO release from the active site of the $\mathrm{FeFe}$ hydrogenases from C. reinhardtii (blue), C. acetobutylicum (red) and M. elsdenii (green).

The change in kinetics of inhibition is not an artifact from heating. Indeed, in control experiments, we observed a current variation of less than $5 \mathrm{nA}(<0.5 \%$ of the value of the current) when the laser diode (any wavelength) was suddenly switched on at maximal power, whereas the catalytic current increases two-fold upon increasing the temperature from $10^{\circ} \mathrm{C}$ to $35^{\circ} \mathrm{C}$, showing that the light-induced temperature variation is lower than $0.1^{\circ} \mathrm{C}$. For Clostridium acetobutylicum, we measured an activation energy for CO release in the dark of $74 \mathrm{~kJ} / \mathrm{mol}$ (in the range $16-32^{\circ} \mathrm{C}$, Supplementary Fig. 20); therefore, a temperature variation of $0.1{ }^{\circ} \mathrm{C}$ increases the rate of $\mathrm{CO}$ release no more than $1 \%$. Incidentally, we note that this value of the activation energy is very close to the value that we calculate in Supporting Information section 2.3 (Supplementary Table 7 and fig 4A) with the small model of the active site.

\section{TDDFT modelling}

We use previously described methods ${ }^{36-38}$ to characterize the electronic structure of the CO-inhibited $\mathrm{H}$-cluster on the basis of the composition and energy diagram of their molecular orbital (MO) (Supplementary Fig. 3a,b). Each $\mathrm{MO}$ can be labelled according to its localization on the $\mathrm{Fe}_{4} \mathrm{~S}_{4}$ or $\mathrm{Fe}_{2} \mathrm{~S}_{2}$ fragment. This classification will help the discussion of the electronic transitions of the $\mathrm{H}$-cluster, which we shall consider as a dyad system, consisting of a $\mathrm{Fe}_{4} \mathrm{~S}_{4}$ cubane covalently linked to the $\mathrm{Fe}_{2} \mathrm{~S}_{2}$ subcluster. 
Scheme 1 depicts the four possible types of electronic transitions in the H-cluster. The fragment localized excitations are those in which the mono-electronic transitions involve $\mathrm{MO}$ localized on a single fragment $\left(\mathrm{Fe}_{4} \mathrm{~S}_{4}\right.$ or $\left.\mathrm{Fe}_{2} \mathrm{~S}_{2}\right)$, while charge transfer (CT) excitations involve $\mathrm{MO}$ localized on different fragments, yielding $\mathrm{Fe}_{4} \mathrm{~S}_{4} \rightarrow \mathrm{Fe}_{2} \mathrm{~S}_{2}$ or $\mathrm{Fe}_{4} \mathrm{~S}_{4} \rightarrow \mathrm{Fe}_{2} \mathrm{~S}_{2} \mathrm{CT}$ states which might decay toward their corresponding CT species.

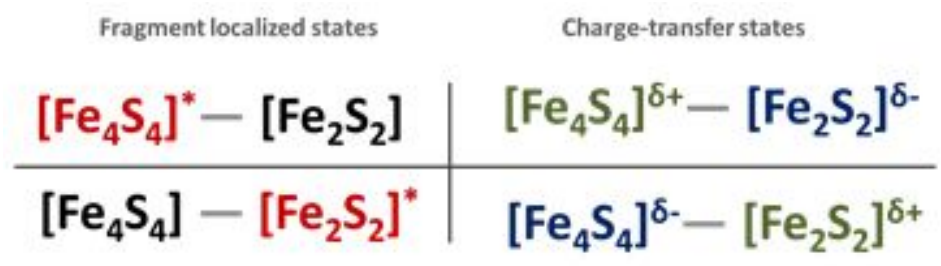

Scheme 1. H-cluster electronic excitation resulting from frontier $M O$ composition. From left: fragment localized (in red) states (on $\mathrm{Fe}_{4} \mathrm{~S}_{4}$ or $\mathrm{Fe}_{2} \mathrm{~S}_{2}$ ), and $\mathrm{Fe}_{4} \mathrm{~S}_{4} \rightarrow \mathrm{Fe}_{2} \mathrm{~S}_{2} / \mathrm{Fe}_{4} \mathrm{~S}_{4} \rightarrow \mathrm{Fe}_{2} \mathrm{~S}_{2}$ charge transfer states.

We shall use scheme 1 to discuss the excitations of the $\mathrm{CO}$ inhibited $\mathrm{H}$-cluster based on their propensity to induce $\mathrm{CO}$ release, which should increase in the order $\mathrm{Fe}_{4} \mathrm{~S}_{4}$-localized $<\mathrm{Fe}_{2} \mathrm{~S}_{2} \rightarrow \mathrm{Fe}_{4} \mathrm{~S}_{4} \mathrm{CT}$ states $<\mathrm{Fe}_{2} \mathrm{~S}_{2} \rightarrow \mathrm{Fe}_{4} \mathrm{~S}_{4} \mathrm{CT}$ states $<\mathrm{Fe}_{2} \mathrm{~S}_{2}$ localized. Indeed, the $\mathrm{Fe}_{4} \mathrm{~S}_{4}$ localized states are inactive with respect to $\mathrm{CO}$ photolysis since the MOs involved do not show any $\mathrm{Fe}-\mathrm{CO}$ orbital contributions (Supporting Information section 2.1). The $\mathrm{Fe}_{2} \mathrm{~S}_{2} \rightarrow \mathrm{Fe}_{4} \mathrm{~S}_{4} \mathrm{CT}$ states can decay via transient $\mathrm{Fe}_{4} \mathrm{~S}_{4}-\mathrm{Fe}_{2} \mathrm{~S}_{2}{ }^{+}$species, which should bind $\mathrm{CO}$ even more strongly than the $\mathrm{H}_{\mathrm{ox}}-\mathrm{CO}$ ground state because the $\mathrm{Fe}(\mathrm{II}) \mathrm{Fe}(\mathrm{II}) \mathrm{CO}$ fragment is undersaturated. In contrast, the decay of the $\mathrm{Fe}_{2} \mathrm{~S}_{2} \rightarrow \mathrm{Fe}_{4} \mathrm{~S}_{4} \mathrm{CT}$ states states toward $\mathrm{Fe}_{4} \mathrm{~S}_{4}{ }^{+}-\mathrm{Fe}_{2} \mathrm{~S}_{2}^{-}$species should result in the formation of a transient $\mathrm{Fe}(\mathrm{I}) \mathrm{Fe}(\mathrm{I}) \mathrm{CO}$ fragment, characterized by lower affinity for $\mathrm{CO}$ and lower dissociation barriers. ${ }^{27,36}$ In the case of the $\mathrm{CT}$ states, the Fe-C bonding MO remains singly occupied and the corresponding potential energy surface (PES) cannot be fully dissociative. The $\mathrm{Fe}_{2} \mathrm{~S}_{2}$ localized states should be the most active toward $\mathrm{CO}$ photolysis because an $\mathrm{Fe}-\mathrm{C}$ antibonding/nonbonding $\mathrm{MO}$ is populated to the detriment of a Fe-C bonding $\mathrm{MO}$, as observed previously in studies of biomimetic models of the $\mathrm{H}$-cluster. ${ }^{27,40}$

To confirm the above model, we computed the electronic spectrum of the full $\mathrm{Fe}_{6} \mathrm{~S}_{6}$ $\mathrm{H}_{\mathrm{ox}}-\mathrm{CO}$ system (fig $1 \mathrm{C}$ ) and a structural model of the CO-bound $\mathrm{Fe}_{2} \mathrm{~S}_{2}$ fragment (fig $1 \mathrm{~B}$ ), the latter either including or excluding the side chains or the residues that form the $\mathrm{H}$-bond network around the dtma and cyanide ligands (Supplementary Figure 11). The relationship between computed excitation energies and experimental wavelength irradiation is proposed in Supporting Information section 2.5, on the basis of the comparison of TDDFT spectra computed for different models (adopting pure GGA BP86 and the hybrid PBE0 functionals) and the UV-vis spectrum of the non-inhibited enzyme. ${ }^{41}$ We must emphasize that the computed excitation energies for the $\mathrm{Fe}_{6} \mathrm{~S}_{6}$ model are not reliable enough for quantitative comparison with the experimental spectrum due to the highly negative total charge of the model, but the nature of the excitations and main mono electronic transitions can be compared to those calculated with the smaller model, e.g. to identify the $\mathrm{Fe}_{2} \mathrm{~S}_{2}$ localized excitations. Indeed, the comparison between BP86 and PBE0 shows the well known blue shift of the excitation energy, but not significant change in the nature of the excited states (Supplementary Figure 12a). 
Considering the $\mathrm{Fe}_{6} \mathrm{~S}_{6}$ model, we computed the first BP86 600 excitations and we observed that most of them are of the $\mathrm{Fe}_{4} \mathrm{~S}_{4}$ localized type (they involve a large number of $\mathrm{Fe}_{4} \mathrm{~S}_{4}$ localized MOs and the excitations are described as $\mathrm{Fe} \rightarrow \mathrm{S}$ or $\mathrm{Fe} \rightarrow \mathrm{S}$ intra-cubane CT states) (Supplementary Table 2). In the low energy part of the spectrum, several weak $\mathrm{Fe}_{4} \mathrm{~S}_{4} \rightarrow \mathrm{Fe}_{2} \mathrm{~S}_{2} \mathrm{CT}$ excitations involve the $\mathrm{Fe}_{2} \mathrm{~S}_{2}$ localized LUMO $\beta$, while the intense band at higher energy results from the superposition of a large number of excitations including $\mathrm{Fe}_{2} \mathrm{~S}_{2}$ localized transitions. In the middle of the spectrum we identify three moderately intense excitations (two $\mathrm{Fe}_{4} \mathrm{~S}_{4}$ localized and one $\mathrm{Fe}_{4} \mathrm{~S}_{4} \rightarrow \mathrm{Fe}_{2} \mathrm{~S}_{2} \mathrm{CT}$ ) that should correspond to the shoulder at $415 \mathrm{~nm}$ in the experimental spectrum. ${ }^{41}$ We conclude that higher energy irradiation is more effective with respect to $\mathrm{CO}$ photolysis because it populates $\mathrm{Fe}_{2} \mathrm{~S}_{2}$ localized states, whereas lower energy irradiation populates $\mathrm{Fe}_{4} \mathrm{~S}_{4} \rightarrow \mathrm{Fe}_{2} \mathrm{~S}_{2} \mathrm{CT}$ states that are not fully dissociative.

This investigation of the $\mathrm{Fe}_{6} \mathrm{~S}_{6}$ model fully supports the "pencil and paper" donor-acceptor model, by confirming the fragment localized and CT nature of the excitations as proposed in Scheme 1. To reach more definite conclusions, we had to explore the excited state surfaces of the $\mathrm{Fe}_{2} \mathrm{~S}_{2}$ model, as described below (unfortunately, we could not investigate the excited PES topology of the relevant states for the large model).

The computed electronic spectrum of the small model (fig. 1B) is dominated by ligand to metal and metal to ligand charge transfer (LMCT and MLCT) excitations (Supplementary Table 5 and 6). To identify the Fe-CO loosely bound excited states, a first approach is to explore the excited PES along the CO dissociation pathways on the ground state PES. Considering the first 20 doublet excitations (hereafter referred to as "nex", with n=1-20), we observed a different topology of the excited PES along the reaction coordinates of apical or equatorial $\mathrm{CO}$ dissociation. Figure $4 \mathrm{~A}$ reports the scans for the apical $\mathrm{CO}$ ligand release. Compared to the ground state,$^{28}$ the lower energy surfaces are loosely bound along the $\mathrm{CO}$ dissociation coordinate. Two series of surface crossings are observed (red arrows), the most evident starting from $5 \mathrm{ex}$, and indicate putative dissociation pathways. The result of the calculation regarding the release of the equatorial CO ligand is shown in Supplementary Figure 13. The energy barrier for the $\mathrm{CO}$ dissociation (estimated from the difference between the excitation energies computed at the beginning and at the end of the PES scan, and averaged over the first 20 excited states) is twice as large for equatorial $\mathrm{CO}$ than for apical CO. Moreover, as described below, the dissociation of the apical $\mathrm{CO}$ along the pathway starting from 5ex appears to be almost barrierless.

We investigated the decay of MLLCT 5ex state by optimizing its structure, taking the ground state geometry as starting point, and then examining the geometry changes that result from each surface crossing (Figure 4B). The apical Fe-C bond is $0.04 \AA$ longer in optimized 5ex than in the structure of the ground state, and the Fe-C-O angle bends 4.7 degree, which supports the dissociative nature of this excitation. This conclusion was further confirmed by TDDFT geometry optimization of the corresponding MLLCT state (12ex) of the $\mathrm{Fe}_{2} \mathrm{~S}_{2}$ model in which side chain residues have been included (Supporting Information section 2.7). After optimization, 5 ex can be considered a 5ex-4ex conical intersection, being only $0.06 \mathrm{kcal} / \mathrm{mol}$ higher than 4ex. Following the pathway depicted as an arrow in Figure 
$4 \mathrm{~A}$, we mimic the vibrational relaxation by a small stretch $(+0.086 \AA)$ of the apical Fe-C to force the crossing, reaching directly the 2ex state. After optimization, the 2ex structure is characterized by a significant lengthening and bending of the apical Fe-CO bond $(+0.183 \AA$, 25.6 degree) compared to the ground state. In a similar manner, we observed the decay of $2 \mathrm{ex}$ to $1 \mathrm{ex}$, where, after optimization, the apical Fe-CO is partially dissociated. The 1ex surface crosses the ground state at $d(\mathrm{Fe}-\mathrm{C})=2.523 \AA$ (Supporting Information section 2.7). At this point, a small amount of vibrational energy should be sufficient to fully dissociate the Fe-C bond.
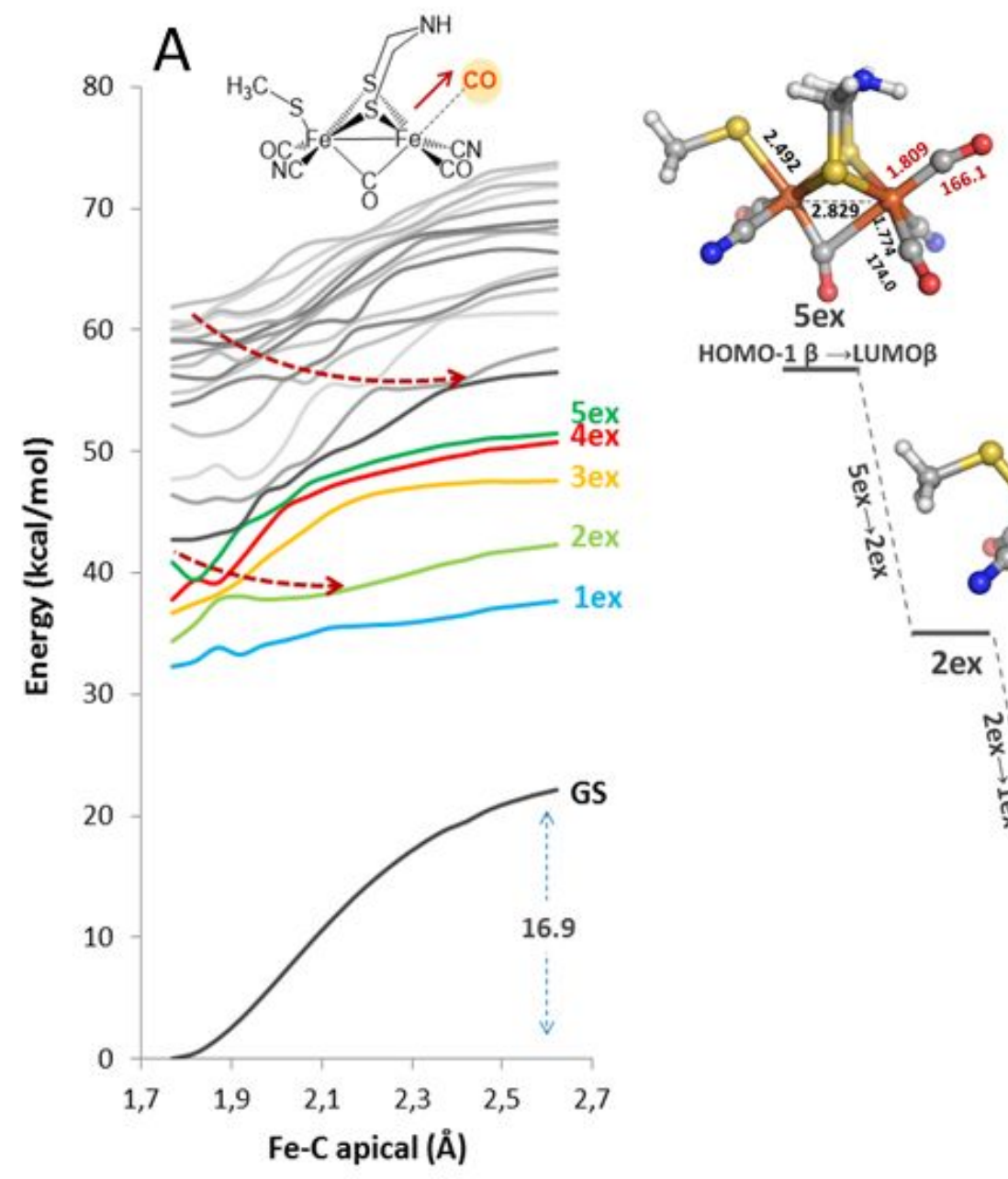

B

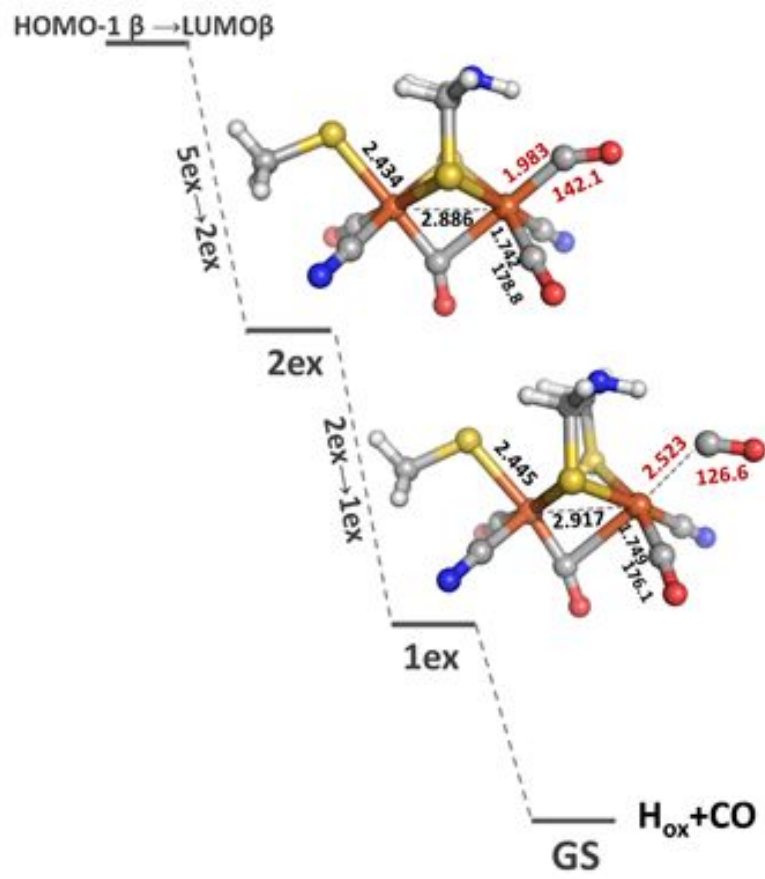

Figure 4. Panel A: potential energy surfaces of the ground state and the first 20 excited doublet states of $\mathrm{Fe}_{2} \mathrm{~S}_{2} \mathrm{H}_{\mathrm{ox}}$-CO model along the apical $\mathrm{Fe}-\mathrm{C}$ stretching coordinate. Energy differences in $\mathrm{kcal} / \mathrm{mol}$, computed with respect to the minimum ground state energy. The value of the free energy dissociation barrier is also reported, and compares well with the experimental value determined in experiments shown in Supplementary Fig. 20. Red arrows guide the eye to follow the dissociation pathway through the surface crossings. Panel B: geometry optimized structures for the $\mathrm{Fe}_{2} \mathrm{~S}_{2}$ fifth (5ex) excited state, along the CO dissociation pathway. Distances in $\AA$, angles in degree. 
The results of the TDDFT investigation of the large $\mathrm{Fe}_{6} \mathrm{~S}_{6}$ model (fig $1 \mathrm{C}$ ) show that the $5 \mathrm{ex}$ in the $\mathrm{Fe}_{2} \mathrm{~S}_{2}$ model investigated above corresponds to a high energy excited state (242ex) in the large model (Supplementary Table 8 and Supplementary Fig. 12a), consistent with the low energy excitations of the $\mathrm{H}$-cluster being ineffective for $\mathrm{CO}$ release. We could not use the large $\mathrm{Fe}_{6} \mathrm{~S}_{6}$ model (fig. 1C) to investigate the $\mathrm{Fe}_{4} \mathrm{~S}_{4} \rightarrow \mathrm{Fe}_{2} \mathrm{~S}_{2}$ CT states because most of our attempts to use the spin-flip approach to optimize the geometry of the broken-symmetry $\mathrm{Fe}_{4} \mathrm{~S}_{4}{ }^{+}-\mathrm{Fe}_{2} \mathrm{~S}_{2}{ }^{-}$species failed. However, we were able to optimize the structure of the 1 ex $\mathrm{Fe}_{6} \mathrm{~S}_{6}$ excited state, converging to a final structure in which the $\mathrm{Fe}-\mathrm{S}$ bond that connects the cubane to to $\mathrm{Fe}_{2} \mathrm{~S}_{2}$ subcluster is $0.13 \AA$ longer than in the ground state, while all other distances are the same. This is consistent with the above qualitative argument according to which the CT states are not involved in CO dissociation.

\section{Discussion}

We have defined the kinetics of the reaction with $\mathrm{CO}$ of the oxidized $\mathrm{H}$-cluster of three distinct FeFe hydrogenases as a function of wavelength in the visible range and light power. The effects are about the same for the three enzymes that we studied despite differences in cofactor compositions: the enzyme from Chlamydomonas reinhardtii bears only the $\mathrm{H}$-cluster whereas the other two have additional electron transferring clusters. ${ }^{1,23,34,35}$ Therefore, our experiments reveal an intrinsic property of the conserved $\mathrm{H}$-cluster. From the point of view of the modelling, this implies that one only needs to investigate the photochemical properties of the H-cluster.

We have characterized before the "dark" kinetics of CO binding to and release from FeFe hydrogenases. ${ }^{29,30,42}$ We have shown that the reaction can be described in terms of intramolecular diffusion of $\mathrm{CO}$ (leading to the reversible formation a "geminate state" with rate constants $k_{1}$ and $k_{-1}$ ), and reversible $\mathrm{Fe}_{\mathrm{d}}-\mathrm{CO}$ bond formation (rate constants $k_{2}$ and $k_{-2}$ ). We used the results of MD and DFT calculations to calculate all four individual rate constants, which we could combine to calculate the value of the rate of inhibition, which compares well with the experimental value.$^{42}$ Regarding the effect of light, the usual method for studying the photodissociation of $\mathrm{CO}$ from inorganic active sites consists in triggering $\mathrm{CO}$ release by a short laser pulse, and following the dissociation and rebinding using time-resolved spectroscopic techniques. Such investigation has only recently been carried out with a FeFe hydrogenase.$^{43}$ In the experiments presented in this paper, in contrast, we measure the steady-state effect of constant monochromatic illumination; the total concentration of enzyme-CO complex is not constant, but continuous irradiation nonetheless leads to a steady-state ratio of [ $\left.\mathrm{E}^{*}-\mathrm{CO}\right]$ over [E-CO] (figure 5 ), which is determined by the competition between excitation, dissociative $\left(k_{-2}{ }^{\text {hv }}\right)$ and non-dissociative $\left(k^{\text {hv }}\right)$ decay. Measuring the global rate of $\mathrm{CO}$ release informs on the nature and reactivity of the excited-state that is formed upon illumination at a certain wavelengths. 


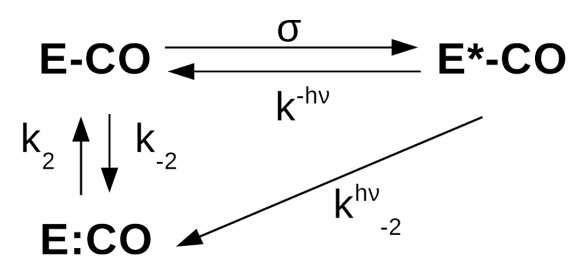

geminate

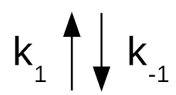

E CO
Figure 5.

Kinetic scheme depicting the various steps that contribute to $\mathrm{CO}$ binding and (photo)release. Step "1" is the formation of a geminate state, from which the $\mathrm{Fe}-\mathrm{CO}$ bond can be reversibly formed. The excited states decay either dissociatively or non-dissociatively.

The simple binding/release kinetic model that we have used to analyse experiments carried out in the dark ${ }^{29,30,42}$ can be fitted to the data recorded with the light on, showing that $\mathrm{E}^{*} \mathrm{CO}$ is in a quasi-steady state. We show in Supporting Information section 4 that the measured values of $k_{\text {in }}$ and $k_{\text {out }}$ are therefore related to the rate constants in fig. 5 by the following relations:

$$
\begin{gathered}
k_{\text {in }}=k_{1} k_{2} /\left(k_{-1}+k_{2}\right) \\
k_{\text {out }}=k_{-1}\left(k_{-2}+k_{-2}^{\text {hv }} \wedge\right) /\left((1+\Lambda)\left(k_{-1}+k_{2}\right)\right)
\end{gathered}
$$

where $\Lambda$ is $\sigma \mathrm{l} /\left(k^{\mathrm{hv}}+k_{-2}{ }^{\mathrm{hv}}\right)$, with I the incident flux of photons, $\sigma$ the cross section for light absorption, $k^{\text {hv }}$ the rate at which the excited states decays without $\mathrm{CO}$ dissociation, and $k_{-2}{ }^{\text {hv }}$ the rate at which the excited state dissociates CO. Our observation that the plot of $k_{\text {out }}$ against $P$ is a line (figure 2D) shows that $\Lambda<<1$, consistent with the low absorption of the $\mathrm{H}$-cluster. We conclude that at the low illumination power that we used, the excited states are populated more slowly than they decay either dissociatively or non-dissociatively.

The absorption coefficient of $\mathrm{H}_{\mathrm{ox}}-\mathrm{CO}$ has not been published but using the spectra of FeFe biomimetic complexes, we estimate $\varepsilon \approx 1 \mathrm{mM}^{-1} \mathrm{~cm}^{-1}$ in the $400 \mathrm{~nm}$ region..$^{9,44,45}$ Using $\sigma=\varepsilon \times \ln (10) / N_{a}$, the value of $\varepsilon$ translates into a molecular absorption cross-section of $4.10^{-22}$ $\mathrm{m}^{2}$ (for all transitions, dissociative and non dissociative). This value is very close to the cross-section for the dissociative absorption of photons, $9.10^{-21} \mathrm{~m}^{2}$ in figure 2, suggesting that, at low wavelengths, most of the absorbed photons lead to photodissociation of the apical CO (thus $k^{\text {hv }}<<k_{-2}^{\text {hv }}$ ).

Thinking of the $\mathrm{H}$-cluster in terms of a $\mathrm{Fe}_{4} \mathrm{~S}_{4}-\mathrm{Fe}_{2} \mathrm{~S}_{2}$ dyad system, a very common model in photochemistry, allowed us to predict which excitations are actually effective for CO release and to identify the relevant excitations in each photochemical process. This description emerges from the analysis of the $\mathrm{H}$-cluster molecular orbitals in a natural manner and will probably prove useful in further investigations of its photochemical reactivity.

The most relevant point in this TDDFT investigation is the reliable correlation between the wavelengths that prove effective in the experiments and the computed excitation energies. We cannot expect TDDFT calculations to quantitatively predict the experimental excitations energies for such a negatively charged large system but this level 
of theory is able to reproduce the features of the experimental absorption spectra available in the literature. ${ }^{41}$

Our calculations clearly show that only the excitations that involve the dinuclear subcluster are active with respect to $\mathrm{CO}$ photodissociation, and these are found at higher energy than the CT states. This conclusion qualitatively agrees with the experimental observation of ours that only irradiation in the high energy part of the visible spectrum increases the rate of $\mathrm{CO}$ dissociation.

Our PES analysis clearly indicates that dissociation of the apical $\mathrm{CO}$ is easier than that of the equatorial or bridging $\mathrm{CO}$. This is not the consequence of the constraints provided by the protein. In the case of the first $\mathrm{Fe}_{2} \mathrm{~S}_{2}$ localized state (5ex in the binuclear model) we could characterize in detail the pathway to the ground state, which is the barrierless release of the apical CO. In support of this result, we observed that if we include first shell residue side chains in the calculation, the excited state that is equivalent to 5ex also shows barrierless apical $\mathrm{CO}$ dissociation (SI section 2.7 and Supplementary Figure 17). These theoretical results are fully consistent with our experimental observation that most violet/blue absorbed photons induce $\mathrm{CO}$ release (figure 3 ).

It has been observed that visible irradiation at very low temperature $(<8 \mathrm{~K})$ also dissociates the apical $\mathrm{CO}$ from $\mathrm{H}_{\mathrm{ox}}-\mathrm{CO}$ but distinct photoproducts (the structures of which were not fully clarified) are formed under certain cryogenic conditions, such as temperature in the range $15-30 \mathrm{~K}^{12-15} \mathrm{~A}$ possible explanation is that in this intermediate range of $\mathrm{T}$, the greater vibrational energy of the system overcomes the barrier for the formation of a second photoproduct, which is not stable at room $\mathrm{T}$ and isomerizes to the most stable form.

Albracht and coworkers ${ }^{14,15}$ have shown that white light damages the enzyme from $D$. desulfuricans, and suggested that this could be a result of the photolysis of one or more intrinsic $\mathrm{CO}$ ligands. We have observed no effect of light (in the wavelength and power ranges described here) on the turnover rate, which suggests that photo-damage might be induced by higher energy and/or longer irradiation. We are now investigating, both theoretically and experimentally, the hypothesis that the UV irradiation might irreversibly inactivate the enzyme by inducing the release of intrinsic $\mathrm{CO}$ ligands or breaking of other Fe-ligand bonds.

TDDFT calculations being particularly challenging, it will be essential that further results be supported by experimental data. For example one may oppose to the calculations presented here that TDDFT cannot describe excited states of double-excitation character, but our experiments actually rule out the relevance of double absorption. Indeed, we observe a linear dependence of the rate of dissociation on light power. Moreover, the absorption of the $\mathrm{H}$-cluster is very weak (light absorption limits the rate of photo-release), making double-excitation very unlikely.

A limitation of our work is the low quality of the excitation energies that are calculated using pure GGA functionals such as BP86 and/or small models of the H-cluster, but our aim was not to reproduce the experimental spectrum, it was to shed light on the first instants of 
the photodynamics of $\mathrm{CO}$-inhibited $\mathrm{H}$-cluster upon irradiation. Here it is more important to describe the nature of the excitations than to accurately calculate their energies.

We believe that in the future, the elucidation of the photochemical processes will also help understanding the reactivity of the active site in the dark, since the main electronic transitions involved in the excited states may occur as transient ground states either in the catalytic cycle or upon formation of inactive states under oxidative or reductive conditions. ${ }^{17,46}$

\section{Methods}

Enzymes. We produced the FeFe hydrogenases from C. acetobutilicum and C. reinhardtii FeFe hydrogenases as described in ref 17 . The enzyme from $M$. elsdenii was heterologously expressed in E. coli and activated as described in ref. 47.

Electrochemistry. We covalently attached the enzymes onto pyrolytic edge graphite rotating electrodes (diameter $1 \mathrm{~mm}$ ) using the method described in ref 31 . We analyzed the electrochemical data using the model in refs 28 and the open source program available at www.qsoas.org. ${ }^{48}$ We used Laser components Flexpoint dot lasers, $\lambda=405 \mathrm{~nm}, 9.5 \mu \mathrm{W}$; $\lambda=450 \mathrm{~nm}, 11.1 \mu \mathrm{W} ; \lambda=532 \mathrm{~nm}, 11.3 \mu \mathrm{W}$ or $\lambda=635 \mathrm{~nm}, 8.1 \mu \mathrm{W}$. The diameter of the parallel beam was $5 \mathrm{~mm}$. The power output could be tuned between 0 and $100 \%$ and measured with a Newton optical power meter 1916-C.

Computational details. The quantum mechanics calculations performed have been carried out with the TURBOMOLE 7 suite of programs. ${ }^{49}$ In particular, DFT and TDDFT calculations were carried out using the BP86 functional and an all-electron valence triple- $\zeta$ (def-TZVP) basis set with polarization functions on all atoms, in conjunction with the resolution-of-the-identity (RI) technique (Supporting Information section 1). Such computational approach proved appropriate for the correct representation of the electronic properties of the $\mathrm{H}$-cluster, both considering binuclear $\mathrm{Fe}_{2} \mathrm{~S}_{2}$ and complete $\mathrm{Fe}_{6} \mathrm{~S}_{6}$ models, as reported in previous works. ${ }^{3,28,38,50,51}$ The broken symmetry approach was implemented to reproduce the proper spin state of the full $\mathrm{H}$-cluster model. ${ }^{36,38,52}$

\section{Acknowledgements}

The French teams were supported by CNRS, Aix Marseille Université, INSA, CEA, Agence Nationale de la Recherche (ANR-12-BS08-0014, ANR-14-CE05-0010, LABEX program ARCANE ANR-11-LABX-0003-01) and the A*MIDEX grant (ANR-11-IDEX-0001-02) funded by the French Government "Investissements d'Avenir" program.

\section{Supporting Information.}

DFT and TDDFT computational details and models. Electronic structures of the models, CO-dissociation computed free energy barriers, TDDFT spectra of $\mathrm{Fe}_{2} \mathrm{Fe}_{2}, \mathrm{Fe}_{2} \mathrm{Fe}_{2}$ with residues and $\mathrm{Fe}_{6} \mathrm{~S}_{6}$ models (BP86 and/or PBE0), PES scans for the apical and equatorial $\mathrm{CO}$ dissociation, explanation of the method used to study the $\mathrm{CO}$ dissociation pathway from 
5ex. Experimental PFV data for the CO-photodissociation for the FeFe hydrogenase of $C$. reinhardtii and $C$. acetobutylicum. Experimental determination of the CO-release activation energy. Kinetic scheme and derivation of the rate constants used in the main text.

\section{Bibliography}

(1) Fontecilla-camps, J. C.; Volbeda, A.; Cavazza, C.; Nicolet, Y. Chem. Rev. 2007, 107, 4273-4303.

(2) Lubitz, W.; Ogata, H.; Ru, O.; Reijerse, E. Chem. Rev. 2014, 114, 4081-4148.

(3) Greco, C.; Fourmond, V.; Baffert, C.; Wang, P.; Dementin, S.; Bertrand, P.; Bruschi, M.; Blumberger, J.; De Gioia, L.; Léger, C. Energy Environ. Sci. 2014, 7 (11), 3543-3573.

(4) Thauer, R. K.; Käufer, B.; Zähringer, M.; Jungermann, K. Eur. J. Biochem. 1974, 42 (2), 447-452.

(5) Pandelia, M. E.; Ogata, H.; Currell, L. J.; Flores, M.; Lubitz, W. Biochim. Biophys. Acta - Bioenerg. 2010, 1797 (2), 304-313.

(6) Nicolet, Y.; Lacey, A. L. De; Vernede, X.; Fernandez, V. M.; Hatchikian, E. C.; Fontecilla-camps, J. C. J. Am. Chem. Soc. 2001, 123, 1596-1601.

(7) Fan, H.; Hall, M. B. J. Am. Chem. Soc. 2001, 123, 3828-3829.

(8) Silakov, A.; Wenk, B.; Reijerse, E.; Lubitz, W. Phys. Chem. Chem. Phys. 2009, 11, 6592-6599.

(9) Berggren, G.; Adamska, A.; Lambertz, C.; Simmons, T. R.; Esselborn, J.; Atta, M.; Gambarelli, S.; Mouesca, J.-M.; Reijerse, E. J.; Lubitz, W.; Happe, T.; Artero, V.; Fontecave, M. Nature 2013, 499 (7456), 66-69.

(10) Lemon, B. J.; Peters, J. W. J. Am. Chem. Soc. 2000, 122 (15), 3793-3794.

(11) Parkin, A.; Cavazza, C.; Fontecilla-Camps, J. C.; Armstrong, F. A. J. Am. Chem. Soc. 2006, 128 (4), 16808-16815.

(12) Chen, Z.; Lemon, B. J.; Huang, S.; Swartz, D. J.; Peters, J. W.; Bagley, K. A. Biochemistry 2002, 41, 2036-2043.

(13) Silakov, A.; Reijerse, E. J.; Lubitz, W. Eur. J. Inorg. Chem. 2011, 2011 (7), 1056-1066.

(14) Albracht, S. P. J.; Roseboom, W.; Hatchikian, E. C. J. Biol. Inorg. Chem. 2006, 11 (1), 88-101.

(15) Roseboom, W.; De Lacey, A. L.; Fernandez, V. M.; Hatchikian, E. C.; Albracht, S. P. J. J. Biol. Inorg. Chem. 2006, 11 (1), 102-118. 
(16) Senger, M.; Mebs, S.; Duan, J.; Wittkamp, F.; Apfel, U.-P.; Heberle, J.; Haumann, M.; Stripp, S. T. Proc. Natl. Acad. Sci. 2016, 113 (30), 8454-8459.

(17) Fourmond, V.; Greco, C.; Sybirna, K.; Baffert, C.; Wang, P.; Ezanno, P.; Montefiori, M.; Bruschi, M.; Meynial-Salles, I.; Soucaille, P.; Blumberger, J.; Bottin, H.; De Gioia, L.; Léger, C. Nat. Chem. 2014, 6 (4), 336-342.

(18) Gust, D.; Moore, T. A.; Moore, A. L. Acc. Chem. Res. 2009, 42 (12), 1890-1898.

(19) Lubner, C. E.; Applegate, A. M.; Knörzer, P.; Ganago, A.; Bryant, D. A.; Happe, T.; Golbeck, J. H. Proc. Natl. Acad. Sci. 2011, 108 (52), 20988-20991.

(20) Ghirardi, M. L. Photosynth. Res. 2015, 125 (3), 383-393.

(21) Lee, C.; Park, H. S.; Fontecilla-camps, J. C.; Reisner, E. Angew. Chemie - Int. Ed. 2016, 55, 5971-5974.

(22) Ciaccafava, A.; Hamon, C.; Infossi, P.; Marchi, V.; Giudici-Orticoni, M.-T.; Lojou, E. Phys. Chem. Chem. Phys. 2013, 15 (39), 16463-16467.

(23) Peters, J. W.; Lanzilotta, W. N.; Lemon, B. J.; Seefeldt, L. C. Science 1998, 282 (5395), 1853-1858.

(24) Li, Y.; Rauchfuss, T. B. Chem. Rev. 2016, 116 (12), 7043-7077.

(25) Kania, R.; Frederix, P. W. J. M.; Wright, J. a; Ulijn, R. V; Pickett, C. J.; Hunt, N. T. J. Chem. Phys. 2012, 136 (4), 44521.

(26) Caplins, B. W.; Lomont, J. P.; Nguyen, S. C.; Harris, C. B. J. Phys. Chem. A 2014, 118 (49), 11529-11540.

(27) Bertini, L.; Greco, C.; Fantucci, P.; De Gioia, L. Int. J. Quantum Chem. 2014, 114 (13), 851-861.

(28) Bertini, L.; Fantucci, P.; De Gioia, L.; Zampella, G. Inorg. Chem. 2013, 52, 9826-9841.

(29) Liebgott, P.; Leroux, F.; Burlat, B.; Dementin, S.; Baffert, C.; Lautier, T.; Fourmond, V.; Ceccaldi, P.; Cavazza, C.; Meynial-Salles, I.; Soucaille, P.; Fontecilla-Camps, J. C.; Guigliarelli, B.; Bertrand, P.; Rousset, M.; Léger, C. Nat. Chem. Biol. 2010, 6 (1), 63-70.

(30) Baffert, C.; Bertini, L.; Lautier, T.; Greco, C.; Sybirna, K.; Ezanno, P.; Etienne, E.; Soucaille, P.; Bertrand, P.; Meynial-salles, I.; De Gioia, L.; Léger, C. J. Am. Chem. Soc. 2011, 133, 2096-2099.

(31) Baffert, C.; Sybirna, K.; Ezanno, P.; Lautier, T.; Hajj, V.; Meynial-Salles, I.; Soucaille, P.; Bottin, H.; Léger, C. Anal. Chem. 2012, 84 (18), 7999-8005.

(32) Léger, C.; Dementin, S.; Bertrand, P.; Rousset, M.; Guigliarelli, B. J. Am. Chem. Soc. 2004, 126 (38), 12162-12172. 
(33) Orain, C.; Saujet, L.; Gauquelin, C.; Soucaille, P.; Meynial-Salles, I.; Baffert, C.; Fourmond, V.; Bottin, H.; Léger, C. J. Am. Chem. Soc. 2015, 137 (9), 12580-12587.

(34) Mulder, D. W.; Boyd, E. S.; Sarma, R.; Lange, R. K.; Endrizzi, J. a; Broderick, J. B.; Peters, J. W. Nature 2010, 465 (7295), 248-251.

(35) Nicolet, Y.; Piras, C.; Legrand, P.; Hatchikian, C. E.; Fontecilla-Camps, J. C. Structure 1999, 7 (1), 13-23.

(36) Fiedler, A. T.; Brunold, T. C. Inorg. Chem. 2005, 44 (25), 9322-9334.

(37) Siegbahn, P. E. M.; Tye, J. W.; Hall, M. B. Chem. Rev. 2007, 107, 4414-4435.

(38) Bruschi, M.; Greco, C.; Bertini, L.; Fantucci, P.; Ryde, U.; De Gioia, L. J. Am. Chem. Soc. 2010, 132, 4992-4993.

(39) Bertini, L.; Greco, C.; Bruschi, M.; Fantucci, P.; De Gioia, L. Organometallics 2010, 29 (9), 2013-2025.

(40) Hunt, N. T.; Wright, J. A.; Pickett, C. Inorg. Chem. 2016, 55 (2), 399-410.

(41) Swanson, K. D.; Ratzloff, M. W.; Mulder, D. W.; Artz, J. H.; Ghose, S.; Hoffman, A.; White, S.; Zadvornyy, O. A.; Broderick, J. B.; Bothner, B.; King, P. W.; Peters, J. W. J. Am. Chem. Soc. 2015, 137 (5), 1809-1816.

(42) Kubas, A.; Orain, C.; De Sancho, D.; Saujet, L.; Sensi, M.; Gauquelin, C.; Meynial-Salles, I.; Soucaille, P.; Bottin, H.; Baffert, C.; Fourmond, V.; Best, R.; Blumberger, J.; Léger, C. Nat. Chem. 2016, August 22nd, DOI:10.1038/NCHEM.2592.

(43) Mirmohades, M.; Adamska-Venkatesh, A.; Sommer, C.; Reijerse, E.; Lomoth, R.; Lubitz, W.; Hammarström, L. J. Phys. Chem. Lett. 2016, 7 (16), 3290-3293.

(44) Roy, S.; Jones, A. K. Nat. Chem. Biol. 2013, 9 (10), 603-605.

(45) Thornley, W. A.; Bitterwolf, T. E. Chem. - A Eur. J. 2015, 21, 18218-18229.

(46) Hajj, V.; Baffert, C.; Sybirna, K.; Meynial-Salles, I.; Soucaille, P.; Bottin, H.; Fourmond, V.; Léger, C. Energy Environ. Sci. 2014, 7 (2), 715.

(47) Caserta, G.; Adamska-Venkatesh, A.; Pecqueur, L.; Atta, M.; Artero, V.; Souvik, R.; Reijerse, E.; Lubitz, W.; Fontecave, M. Biochim. Biophys. Acta 2016, 1857 (11), 1734-1740.

(48) Fourmond, V. Anal. Chem. 2016, 88, 5050-5052.

(49) Ahlrichs, R.; Bär, M.; Häser;, M.; Horn;, H.; Kölmel, C. Chem. Phys. Lett 1989, 162 (3), 165-169.

(50) Stiebritz, M. T.; Reiher, M. Inorg. Chem. 2009, 48 (15), 7127-7140.

(51) Liu, C.; Liu, T.; Hall, M. B. J. Chem. Theory Comput. 2015, 11 (1), 205-214. 
(52) Bruschi, M.; Greco, C.; Fantucci, P.; De Gioia, L. Inorg. Chem. 2008, 47 (13), 6056-6071 